\title{
Uma produção de significados sobre a síndrome de Down
}

\author{
Production of meanings related \\ to Down syndrome
}

Maria Helena Cabral de Almeida Cardoso 1

\footnotetext{
${ }^{1}$ Departamento de Genética, Instituto Fernandes Figueira, Fundação Oswaldo Cruz. Av. Rui Barbosa 716, Rio de Janeiro, $R J$ 22250-020, Brasil. mhc@unisys.com.br
}

\begin{abstract}
This article explores how medical and lay discourses make themselves intelligible by using figures of speech and jointly constructing a socially homogeneous idea of children with Down syndrome, based on an ethnographic study performed at the Down Syndrome Out-Patient Clinic in the José Carlos Cabral de Almeida Center for Clinical Genetics, part of the Department of Genetics at the Fernandes Figueira Institute, a Federal reference hospital for maternal and child health belonging to the Oswaldo Cruz Foundation.
\end{abstract}

Key words Cultural Anthropology; Metaphor; Down Syndrome

Resumo Partindo de uma abordagem etnográfica, realizada no Ambulatório de Síndrome de Down do Centro de Genética Médica José Carlos Cabral de Almeida, do Departamento de Genética do Instituto Fernandes Figueira, unidade materno-infantil da Fundação Oswaldo Cruz, este artigo objetiva explorar como o discurso médico e leigo tornam-se inteligíveis via o uso de figuras de linguagem, e articulando-se constroem uma idéia social homogênea da criança com síndrome de Down.

Palavras-chave Antropologia Cultural; Metáfora; Síndrome de Down 


\section{Introdução}

Este trabalho voltou-se para analisar as narrativas elaboradas por um geneticista clínico e seus pacientes sobre a síndrome de Down, produzindo, com base nelas, registros de significados sobre aqueles que a portam.

O ponto de partida foi conceber que a história do adoecer, tanto para os especialistas quanto para os leigos, se constrói na medida em que estilos culturais diferentes entrelaçam-se e absorvem-se mutuamente, apesar da distância variada dos lugares sociais de onde provêm e da hegemonia do saber médico sobre a doença e os doentes. Mais precisamente tratava-se, via uma observação continuada, de constatar a existência do que Ginzburg (1989) propõe ser uma "circularidade de idéias": de um lado, haveria os pacientes deslocados de seus lares para o hospital, perpetuando a tradição popular e mesclando-a ao contato com o especialista; de outro, esse próprio especialista, valendo-se de sua formação profissional, transmitindo aos pais, cujos filhos estão objetivados por sua doença, signos, códigos, metáforas também usados na linguagem comum, só que produzindo significados diferentes.

O que segue é a apresentação da análise sobre o que foi observado, colocando-a sob títulos, por vezes, propositadamente metafóricos, logo após uma descrição metodológica sobre o trabalho de observação empreendido. Procede-se, portanto, a um percurso encetado em cima de um diário de campo, visando trazer à tona as experiências vivenciadas pela autora da pesquisa e por aqueles que permitiram que ela os observasse, tendo sempre a intenção de captar os sentidos dados ao adoecer, por uma condição geneticamente determinada, quando se o vive cotidianamente.

\section{A construção dos registros etnográficos}

O trabalho etnográfico foi realizado no Ambulatório de Síndrome de Down, do Centro de Genética Médica José Carlos Cabral de Almeida, do Departamento de Genética do Instituto Fernandes Figueira, unidade materno-infantil da Fundação Oswaldo Cruz, por um período de dois anos e meio consecutivos. A observação foi levada a cabo toda quarta-feira pela manhã, estendendo-se de 9:00 às 12:30, tendo sido anotadas no caderno de campo um total de 908 consultas acompanhadas. Só foram objeto de análise os encontros entre pacientes e médico geneticista, pertencente ao quadro institucional, com experiência comprovada de mais de vinte anos de atendimento a pacientes com doenças genéticas.
O recorte do fator experiência obedeceu a critérios de ordem metódica. Por um lado visava-se atingir uma maior acuidade na observação de como a percepção dos sinais cardeais, mais claramente articulados à síndrome, faziam-se constituintes da certeza clínica/diagnóstica e da capacidade de transmiti-la; por outro, o quanto a maior bagagem do médico poderia oferecer ao observador meios de registrar as trocas intersubjetivas, entre ele e os pais, constituintes de uma rotina de assistência já estabelecida há muitos anos. Em outras palavras, almejava-se avaliar, no âmbito do serviço estudado, se a repetição no atendimento ao cliente com o mesmo tipo de anomalia cromossômica havia "robotizado" os postulados da semiologia médica, enrijecendo as peculiaridades individuais e ditado comportamentos tecnicamente estandardizados por parte do médico, dentro da moldura de uma doença cuja carga de sofrimento, para os pais, familiares e amigos de seus portadores, abrange um arco bastante distendido de preconceitos, dúvidas, responsabilidades, anseios, frustrações, desânimo, temores...

Desde o início, entendeu-se por etnografia um exercício prático peculiar de compreensão da realidade sócio-cultural dos outros, mediante a análise da própria experiência de estar no mundo deles. Nesse sentido, tratou-se de uma abordagem ao mesmo tempo reflexiva e interpretativa, tomando por base o processo de transformar as conversas, as observações e as experiências em textos escritos.

A inserção no campo representou a intencionalidade de se focar um determinado grupo de pacientes e seu médico, assumindo-se, declaradamente, o papel que Adler \& Adler (1998: 84) denominam "observador como participan$t e$ ". A emersão no campo correspondeu ao objetivo de coletar dados, interagindo somente ocasionalmente e de forma não diretiva com os observados, conversando de forma aberta e espontânea com eles, tendo-se muitas vezes, por exemplo, após terminadas as consultas, trocado idéias com o médico - às vezes por solicitação dele e, outras, por iniciativa da pesquisadora que procurava maiores esclarecimentos sobre determinadas questões que emergiam da observação. A todos foi explicitada a presença da pesquisadora no set da consulta, tendo sido esclarecidos os propósitos da pesquisa e facultada a liberdade de vetar sua participação, caso fosse desejado, assim como seu compromisso em manter anônimas as identidades dos pacientes e seus pais, como também manter sigilo sobre as informações médicas concernentes ao estado clínico dos primeiros. 
No que diz respeito à análise do material coletado, principiou-se a leitura semiótica de todas as notas enquanto um corpus, considerando todo o registro da experiência de campo tal como ela se desenvolveu no decorrer do tempo. Nela, aplicaram-se procedimentos de codificação qualitativa analítica, comuns na análise de documentos históricos e que, basicamente, compreendem uma codificação aberta, processada pela leitura linha por linha das anotações, com a finalidade de identificar e formular as idéias, os temas e os assuntos que elas sugerem e uma codificação enfocada, tendo por base tópicos já identificados como de particular interesse.

\section{Os anjos}

As crianças com síndrome de Down, normalmente são apresentadas como cordatas, afetuosas, meigas, brincalhonas, portadoras de lições de vida, impulsionadoras de modificações profundamente humanitárias em seus pais e parentes, inclusive, literalmente sendo chamadas de "anjos" em diversas ocasiões, como entrevistas que se concedem sobre elas, em livros que sobre elas se escrevem, ou na consulta médica. "Ela é a luz da minha vida"; "Deus nos mandou esse anjo"; "Ele é quem me ensina” são expressões registradas no diário de campo, dentre muitas outras, que indicam claramente esse tipo metafórico de construção social da criança com síndrome de Down.

Um anjo não é ser normal. Ele é superior aos homens e paira acima deles. Sua inocência o faz arauto de boas novas, ao mesmo tempo que culturalmente lhe é imputada a função de proteger os bons e os inocentes. A metáfora do "anjo" é, pois, uma metáfora de defesa e de compensação para o sofrimento sentido e testemunhado. É verdade que as pessoas costumam se referir aos recém-nascidos, aos bebês e aos infantes como anjos, porém, no que toca à síndrome de Down, tal metáfora conota dimensões peculiares adscritas a um gestaltismo constituinte da condição. Dá-se uma construção da diferença/especialidade transcendente ao valor individual que cada filho tem para seus pais, pois vinculada diretamente a uma situação inexorável ditada pela contingência, isto é, um "erro da natureza". E este "erro" demanda uma certa razão para ter acontecido. A genética descreve e explica os mecanismos dele, dando conta cientificamente do que pode ter acontecido; entretanto, para a maioria dos pais, até por reforçar o cunho "acidental”, não responde ao grande "por que comigo?"

A observação empreendida indica que a instrumentalização metafórica do "anjo”, trans- cendendo a questão comportamental, enraízase no "especial", qualidade de que a cultura dotou essas crianças e que é agenciada pelos pais, (re) arrumando o usualmente conotado como negativo para um positivo que une "especiais", ou seja, ter se tornado mais humanamente "especial” por ter uma criança "especial”. Uma das mães atendidas, durante a fase etnográfica desta pesquisa, exemplifica esta perspectiva, quando opera uma divisão entre o mundo "especial" e o mundo "normal", declarando que do lado de fora das fronteiras do primeiro, o geneticista que a atendia era um dos poucos capazes de entender a verdadeira dimensão das qualidades embutidas no "especial". "Nossas crianças são especiais. O senhor conhece muito bem nossas crianças é é muito difícil achar alguém assim." e, posteriormente, após a prescrição de Advil para minorar as cólicas menstruais da filha: "Pode também ser dado para os ditos normais? Porque, afinal, nossas crianças são muito mais normais que as outras pessoas". A relação que se estabelece entre os "ditos normais" e as crianças com síndrome de Down, tendo como padrão a idéia da normalidade e com os segundos predominando sobre os demais, ressalta a concepção positiva do "especial”, reforçando-a por traços de temperamento tidos também como determinados pelo "acidente genético" e que são muito mais humanitários, tais como a espontaneidade, a afetividade, a ingenuidade, a alegria.

\section{A colheita de uvas em Arles - misérias humanas}

A concepção do “especial”, porém, não se dá de imediato. Ela se constrói na rede tecida pelo tempo, acontecimentos, pessoas, corpos, doenças, médicos, instituições, depois de diversas etapas terem sido ultrapassadas e diversas narrativas terem sido encetadas e (re)encetadas. E ela não é unívoca.

Em muitos casos a metáfora do anjo não se agencia, e a noção de doença se sobrepõe à da condição geneticamente dada. Nesses casos a tônica é trágica e uma espécie de conformidade submissa molda a atitude dos pais, refletindo-se no desenvolvimento físico, psicomotor e social das crianças. Em geral, as perguntas feitas pelo médico são respondidas por monossílabos e a experiência clínica precisa ser instrumentalizada para que se avalie a dimensão do adquirido. O exame físico, nessas situações, é bastante cuidadoso porque as evidências apontam para o descuido até com relação a questões higiênicas básicas. De uma certa forma, embora o centro da consulta seja a criança, em 
situações desse tipo, a inquirição desvia-se dela para repousar no cotidiano familiar. Não foram poucas as vezes em que se observou o geneticista questionar a saúde materna, as condições de trabalho, a renda familiar, a possibilidade de ajuda por parte de parentes e vizinhos. Nesses momentos, a noção de doença como entidade mórbida, soerguida pela formação profissional, é atravessada pela idéia do indivíduo e de seu adoecimento enquanto sobredeterminados por uma sociedade excludente cujo próprio corpo é e está doente. $\mathrm{O}$ inato separa-se em definitivo do adquirido. E este vincula-se ao coletivo, enquanto modulador da miséria humana.

A associação entre a deficiência mental e pobreza não é mais encarada como atávica, como outrora já o foi, mas a não melhoria do desenvolvimento psicomotor e da sociabilidade é tida como de responsabilidade do social. E o retardo nunca cessa de ser ícone e índice do sofrimento e da miserabilidade da condição humana.

Paul Sweetman (1998), um dos biógrafos de Paul Gauguin, discorrendo sobre um dos quadros do pintor intitulado Colheita de Uvas em Arles, usa para descrever a figura central do quadro, uma menina sentada no chão com o rosto apoiado nas mãos, as seguintes palavras: "os olhos apertados e o rosto apático lembram o de uma vítima da síndrome de Down" (Sweetan, 1998:227). É, portanto, a imagem da criança com síndrome de Down a apropriada por ele para despertar na mente do leitor o impacto do sofrimento retratado por Gauguin e, inclusive, para explicar o fato de ele ter dado um segundo título à sua pintura, como a afirmar que mesmo pintando paisagens como Van Gogh, o que lhe angustiava era a condição humana. $\mathrm{O}$ subtítulo foi: Misères Humaines e passou a identificar o quadro até hoje.

Não se trata de afirmar que o propósito de Gauguin foi o de retratar uma criança com síndrome de Down, mas tão somente constatar quanto a síndrome, ainda hoje, é mobilizada como símbolo da miséria humana. Sem dúvi$\mathrm{da}$, o rosto, representado na pintura, lembra o semblante típico da síndrome e as vestes e a postura da menina como que impelem quem a contempla a pensar "pobre criatura!", como, de resto, é a forma com que Sweetman (1998) se refere a ela repetidamente.

Esta imagem e o sentimento de piedade que desperta são difíceis de serem apagados, por isso a metáfora do anjo, para muitos, ainda que inconscientemente, consola e traz esperança. Ela não tem que ser refutada, nem censurada. Dimensioná-la é também entender o seu opos- to, a "pobre criatura" que se mistura com a própria condição de miserabilidade dos pais, sentindo-se tão ou mais "pobre criaturas" que ela.

Tal miserabilidade, muitas vezes, sem qualquer sombra de queixume, se impõe como dado à anamnese. Um exemplo, retirado dentre muitos outros, refere-se a uma criança com vinte e um dias. A mãe tinha cinqüenta e dois anos e o pai quarenta e sete. Juntos haviam tido dez filhos. O mais velho faria trinta anos, mas havia sido assassinado aos vinte e dois. A que o seguia tinha vinte e nove anos e era mãe de quatro filhos, duas meninas e dois meninos. Depois dela vinha um com vinte e três anos que também tinha dois filhos. Logo em seguida haviam tido dois homens, ambos atualmente solteiros, seguidos de uma menina que teria, à época da consulta, vinte e dois anos, mas que havia falecido de desidratação. Após esta menina haviam tido mais um homem, uma outra menina que estava com treze anos, outro menino, agora com cerca de três anos e o paciente. A gravidez havia transcorrido sem problemas e o menino tinha nascido de parto cesáreo, visto que resolveram que ela iria "ligar as trompas".

Todos os acontecimentos foram narrados em tom normal e o geneticista ia elaborando o heredograma, à medida em que as informações iam sendo relatadas. $\mathrm{O}$ assassinato do primeiro filho, a morte por desidratação da outra filha não foram contados porque havia o propósito de despertar a simpatia ou tornar patente uma história familiar de perdas e de lutas, diante da circunstância de na pobreza terem gerado dez filhos, mas tão somente porque havia a necessidade, por parte do médico, de saber a história familiar para poder determinar se havia indicações que pudessem sugerir algum tipo de doença genética na família. No caso, a pergunta sobre a razão de terem sido enviados ao Ambulatório, foi respondida de forma simples e direta: "Disseram que ele teve probleminhas; que nasceu com uma doença genética, por isso também teve probleminhas de coração. Estamos aqui para fazer o exame".

O mundo de inferências que se pode tirar desse breve relato revela o quanto, dentro do campo do exercício médico, se dá a construção de um enredo saturado de produções de sentido que transcendem o que se chama de "orgânico", embora dele também sejam constituintes.

A passividade aparente dos pais articulavase à constatação de uma realidade que lhes fora informada e que eles próprios constatavam. A implosão da ciência e da técnica uma para dentro da outra (Haraway, 1997), característica do estilo de pensamento que atualmente dita o 
que é científico e, portanto, inquestionável, impulsionara o médico que os havia atendido, por ocasião do nascimento do filho, a lhes informar que deveriam procurar o geneticista já que havia um exame a ser feito, quando a realidade clínica era patente. Para a lógica da tecnociência, a doença só se materializa quando a interioridade é exteriorizada via as mais variadas técnicas de perscrutação. No caso da síndrome de Down, os sinais evidentes da superfície mais visível só seriam comprovados por aqueles visualizados na superfície da lâmina, produzidos pela mediação da cultura celular, do microscópio ótico, da fotomicrografia, do recorte dos cromossomos e da montagem do cariótipo. A ilusão é pensar que esta viagem para o espaço interior, no tocante à síndrome de Down, seja condição sine-qua-non do diagnóstico. Até porque, conforme argumenta Haraway (1997), as células, genes, moléculas, dentre outros organismos biomédicos, são específicos corpos materiais-semióticos, ou objetos técnico-naturais de conhecimento e prática, produtos dos mais variados processos de trabalho das tecnociências, tais quais os sinais aparentes à visão treinada também o são.

A medicalização progressiva, alimentada pela velocidade do turbilhão tecnológico sempre em avanço, engendra novas maneiras de pensar a si próprio, os outros e o mundo, só que o compasso desse dinamismo não tem a mesma cadência para todos. Para a população que demanda os serviços do Ambulatório de Síndrome de Down, do Instituto Fernandes Figueira, a visão orgânica da doença predomina, sendo o médico aquele que sabe quais exames pedir para revelar o oculto. Por princípio, o médico é o detentor do saber acerca da doença; contudo, não é ele quem conhece o corpo doente. O que ele faz é mediar o processo de dar maior inteligibilidade a este corpo visto que detém os meios para nele penetrar. Mas esta penetração só é entendida até o nível dos órgãos. E a leitura que se faz em cima daquela feita pelo especialista é localizada, a saber, parte da experiência de cada um moldada na historicidade de ser humano. O cromossomo extra fica no território do verbalizado, sem que seja, pela maioria, dotado de materialidade. Ele metaforiza-se no "acidente genético", determinando uma condição que se concretiza nos "problemas" que afetam os órgãos, sejam eles o cérebro, sempre entendido como a "cabeça”, o coração e os "intestinos".
Os corpos, a normalidade, a organização

e o futuro no presente

No caso da síndrome de Down o corpo doente, para o resto da vida, pertence também aos pais. Mesmo quando se trata de adolescentes, são os responsáveis quem dele dão conta. Até quando há um bom nível de articulação por parte do paciente, o hábito enraizado faz com que o médico sem se aperceber, e em que pese seu discurso pró estimulação contínua e inclusão, sempre se dirija aos pais que instintivamente arrogam a si falar pelos filhos e agir por eles. Assim é muito comum ser a mãe a retirar a roupa da criança, até quando é reportado que ela, em casa, já cuida de si sozinha.

Existem pais que almejam dar conta das conquistas dos filhos, enumerando logo no início da consulta os progressos atingidos, refletindo um nível de expectativa em constante ebulição. E há aqueles nos quais o desânimo se instaura e a condição genética passa a ser a explicação para a estagnação do desenvolvimento psicomotor e social dos filhos. Em ambas as situações foi possível observar um processo de metonímia pelo qual toma-se o filho por si mesmo. É evidente que essa sensação de se ter o filho como "obra" é normal e, de certa maneira, é vivida por todos os pais. Nos casos dos pais com filhos com síndrome de Down ela é mais contundente, pois a realidade da condição dos filhos, de alguma maneira, desperta a impressão de neles estar refletida a própria competência reprodutiva. Esta "obra” é corpórea e mentalmente diferente, "especial”, tornando sócio-coletivamente mais manifesta a responsabilidade por sua "autoria”. Por isso, em certos casos, quando do diagnóstico, o "acidente genético" é algo da ordem do dito mas não do credível. Uma das mães afirmou: "Eu tenho vinte e sete anos ele trinta. É a minha primeira gravidez. Quando ele nasceu, disseram que tinha problema no coração. Depois a pediatra falou que ele tinha síndrome de Down. Eu não acredito nesse segundo problema, só no do coração, no sopro". Mas ela própria também havia dito que reparara, logo que vira o filho pela primeira vez, que "tinha olhinhos de japonês". E quando o médico confirmou: "Seu filho tem síndrome de Down", a resposta foi: "Eu sei que ele tem sopro", permanecendo calada o resto da consulta.

Acontece durante a consulta médica um "intervalo" no tempo, durante o qual o corpo do filho não parece pertencer nem a ele, nem aos pais. Há como uma imobilização, um pairar no ar, uma "desencarnação" e ele passa a ser aquilo que está sendo escrito no papel pelo médico. É o momento da elaboração do prontuário. 
O corpo enfermo torna-se do médico porque ele é o representante da medicina e ela é a dona da doença. Ela é dona porque se acredita que conheça. E seu conhecimento é pertinente a um mundo de códigos que só o especialista pode decifrar. Ele detém as "chaves do mistério". Do "crime" cometido pela "natureza" ele é o investigador. Os rastros que segue, os indícios que cuidadosamente anota são partes constituintes daquele ser que, agora, é seu objeto. O silêncio é absoluto e os minutos parecem serem medidos pela quantidade de linhas que se acumulam no papel. É para ele que os olhos se dirigem. Ali estão os signos, os fragmentos das evidências, o que Ginzburg (1991) chama de o documento enquanto individualidade, porque relacionado com o qualitativo, com a singularidade, com o caso.

Quando terminam as anotações, o senso dos corpos, do local, do tempo, das pessoas ao redor retorna. Mas o que foi escrito perdura intocado e sobre ele nada se pergunta e se fala. Espera-se a conclusão e só então começam as perguntas que irão esclarecer qual foi ela e o que, a partir dela, deverá ser feito. Normalmente, se o filho é um bebê de colo é erguido mais alto, olhado e trocado de posição; se já anda ou é adolescente sempre há uma chamada de atenção, quer via um afago, quer via algumas palavras. Inicia-se uma conversa na qual as questões pertinentes ao estado de saúde atual são as que predominam. O sentido é bem aquele exemplificado por uma mãe que, quando o médico começou a falar sobre a síndrome de Down, respondeu-lhe que com a síndrome a criança "nasce, cresce e morre com ela. Mas o coração pode matar agora”.

Nas consultas que não se referem ao diagnóstico ou à sua confirmação, são os problemas correlatos à síndrome que são os abordados. A preocupação sempre se centra nas intercorrências, tais como os resfriados constantes, a pele seca, o intestino preso, as otites, as dermatites, a queda do cabelo. Receitas caseiras são trazidas para o médico que as escuta com atenção, como, por exemplo, o reporte de que a ingestão de geléia de mocotó havia melhorado a alopecia que se viu ser referida pelo geneticista a uma outra mãe, passados alguns meses. Somente em três casos foi perguntado diretamente ao médico qual havia sido o resultado do exame laboratorial de checagem da função tireoidiana. A regra era essa informação partir dele, sem que se manifestasse interesse pelo assunto. A ingestão do hormônio, no caso, já era a solução para o problema.

É também no após elaboração do prontuário que, habitualmente, se retoma o discurso sobre as conquistas. Termos como "levado", "bagunceiro”, “impossível”, "genioso”, com grande reincidência do primeiro, são verbalizados como metáforas/sinais de normalidade. É freqüente exigir-se da criança a demonstração de seus avanços, sem que o geneticista o tenha requerido. "Fala para o titio que filme você gosta de ver"; "Fala rua para ele ouvir"; "Dê um beijo na mamãe"; "Dá tchau para a moça”, são exemplos escolhidos ao léu.

O cuidado no trajar e o uso de roupas da "moda", sobretudo estampando heróis de desenhos animados (Pokemón, Minnie, Mickey etc.) mostram que essas crianças são vestidas como outras de mesma idade. Os meninos, geralmente, portam bermudas largas e camisetas de "camuflagem"; as meninas, normalmente, vestem saias curtas e os cabelos são enfeitados por pregadores e elásticos coloridos. Todos gostam de exibir suas roupas e mostram-se muito satisfeitos quando o médico os elogia. A ida ao médico é um evento para o qual as mães se preparam e preparam suas crianças. Observouse que o aplauso espontâneo do médico é, para as mães e/ou responsáveis, tão recompensador quanto a demonstração, por parte da criança, dos avanços que ela alcançou.

Outro tópico/tropo na narração da "normalidade" sonhada é a metamorfose das características dos filhos naquelas de pais e parentes. Passado o impacto do diagnóstico, a relação cotidiana com a criança evidencia para os pais uma tônica do discurso do médico que é apagada, no primeiro momento, pela construção sócio-cultural da síndrome de Down. Como tal construção é uma "idéia”, a homogeneidade tende a apagar a diferença entre os "diferentes".

Em todas as primeiras consultas, o médico salientou a heterogeneidade, fazendo questão de perguntar “Com quem ela se parece?", mesmo quando se tratava de um recém-nascido. A reposta era o silêncio ou um murmurado "não sei". Diante das duas, o geneticista comentava que, realmente, as pessoas quase sempre têm a impressão de que os bebês são todos iguais, mas que com o tempo as semelhanças se fariam sentir, pois como qualquer outra criança, aquela com síndrome de Down portava traços herdados. Diante dessa afirmação, o olhar era de espanto e incredulidade. No entanto, quando da segunda consulta, passado um período determinado pelo médico e que variava de acordo com o quadro clínico da criança, observou-se que os pais davam razão a ele, apontando a similitude quer física, quer comportamental do filho com um deles ou com outro membro da família. Essa constatação, à proporção que o bebê cresce, como foi registrado nas con- 
sultas de acompanhamento referentes às crianças com mais de dois anos de idade, ganha maior intensidade, só que ela é sempre metáfora, signo/ícone da "normalidade" tanto quanto as já aludidas qualificações de "levado", "teimoso", "bagunceiro" etc. o são.

Pesar, inadequação, descrença, revolta, incerteza, perplexidade, rejeição, constrangimento, raiva, hostilidade, impotência compõem o que se sintetizou no diário de campo, processados seis meses de pesquisa etnográfica, como "os estrondos do silêncio". São os sentimentos que reverberam e ensurdecem os pais tão logo o diagnóstico é confirmado. Após serem revistas todas as anotações, nada foi achado que pudesse modificar esse registro inicial. O silêncio que se segue ao diagnóstico é qualitativamente diferente daquele que se faz presente quando o médico está redigindo o prontuário. Ele não paira e não é “descorporificado”. Ele é um silêncio preenchido de sons fortes, interiorizados, que se refletem nos rostos como se esses fossem potentes antenas amplificadoras de sinais. A voz do médico é completamente abafada. É necessário um tempo para ela transpor os estrondos e conseguir se fazer ouvir.

A afirmativa categórica: "Seu filho tem síndrome de Down” é seguida por uma longa pausa. Lentamente, então, começa o que, também desde as primeiras anotações, categorizou-se como "organização". A doença, percebida pelo médico como processo, demanda ser "organizada” por ele e pelos pais. Essa organização é transmitida via o arrolar de ações, colocadas numa determinada ordem, classificadas como de longo, médio e curto prazos.

As primeiras e mais urgentes compreendem a consulta ao cardiologista para o empreendimento do estudo ecocardiográfico, a realização da ultra-sonografia abdominal e o registro no hospital, a fim de a criança poder ser mantida em acompanhamento pelo geneticista. O conjunto dessas primeiras intervenções é justificado, para os pais, pela necessidade de se "afastarem certos problemas orgânicos que a síndrome provoca". As segundas abarcam o contato imediato com outros pais que têm filhos com síndrome de Down e a estimulação precoce, sendo os pais encaminhados à assistente social para esta indicar-lhes um lugar próximo a suas casas, onde um profissional especializado irá atendêlos e a seus filhos. Finalmente pautam-se as ações a longo prazo, significando basicamente o que esperar do futuro imediato. Certas informações concernentes à fala, a problemas comportamentais, à implantação dos dentes, aos procedimentos terapêuticos, à reação das demais pessoas, entre outras questões, são veiculadas.
Durante toda a exposição da "organização", o papel dos pais é ressaltado, assim como a não-existência de um "padrão" de criança com síndrome de Down. A individualidade e as necessidades pertinentes a qualquer bebê são bastante reforçadas. A designação "síndrome de Down” é empregada repetida e sistematicamente, como uma estratégia à introjeção/realização do diagnóstico, mas também não deixando de soar como um reforço à homogeneidade, unificando os indivíduos pela características nosográficas de sua doença, opondo ao vulgar "mongolismo" a denominação médica/científica da síndrome.

Por parte dos pais a principal preocupação é com o que nomeiam "grau" do retardo mental. A noção generalizada é que o cariótipo responderia ao "problema da cabeça". Como a maioria dos pais é recebida no Ambulatório por pediatras, neurologistas e outros profissionais de saúde que prestaram atendimento previamente, é por eles informada de que existe " $u$ m exame para a síndrome" e o associam à medição da marca que socialmente sintetiza a condição de seus filhos. Essa idéia de gradação do retardo permanece, mesmo com o desenrolar do tempo, sendo as conquistas sempre mediadas pelo avanço e/ou retrocesso das manifestações relacionadas ao desempenho intelectual.

O futuro só é questionado dentro de um arco muito reduzido de tempo. O presente ou o imediato amanhã prevaleceram, nunca tendo sido observado serem dirigidas ao geneticista perguntas sobre a vida adulta ou doenças que porventura poderiam advir em função da anomalia de base. O passado foi ultrapassado cronologicamente, mas penetra no agora, tornando-se parte constituinte dele. Retorna sempre no momento do exame físico e da elaboração do prontuário, permeando também as conversas introdutórias e finais da consulta.

A problemática da sexualidade serve bem para explanar a ansiedade projetada nesse futuro que se expressa no presente. Foram os pais de pacientes com idades variando entre oito e quatorze anos aqueles que manifestaram suas preocupações, e estas eram basicamente articuladas, quando das meninas, à menstruação e ao namoro e, quando dos meninos, à masturbação.

Para as mães com filhas de oito anos a puberdade é motivo de questionamento ao médico, a fim de obterem diretrizes à condução do que fazer diante da primeira menstruação que poderia estar se aproximando. O foco é muito mais o comportamento do que aspectos fisiológicos ou emocionais que poderiam advir da experiência. Uma das mães disse ao geneticista 
que tinha ficado menstruada pela primeira vez aos nove anos de idade e que, agora, temia que o mesmo acontecesse com a filha, pois "eu sabia como me comportar", deixando implícito o temor da exposição aos outros e seu medo de fracassar na proteção da intimidade da filha. Era a própria experiência, o passado, que a levava a interrogar o futuro visto como quase de imediato. Nenhuma interrogação acerca da fertilidade ou do desejo sexual foi colocada. O que impulsionava era o pragmatismo. Tornavase necessário saber como se conduzir para conduzir a filha.

A resposta do médico, diante de casos como esses, sempre foi a de que é preciso ensinar e explicar, de forma paciente e cuidadosa; entretanto, considerando todo o tempo o potencial de cada um. Novamente a heterogeneidade era ressaltada no que tange ao desenvolvimento físico, emocional, psicomotor, mental e social, assim como era sublinhada a ingerência do meio familiar e grupal no comportamento do paciente. Nesses casos o adquirido ganhava relevância sobre o inato, não ocorrendo nenhuma informação, por parte do médico, que ultrapassasse os limites da questão colocada. Reafirmava-se a "organização", introduzindo mais uma vez a idéia de etapas/ações a serem experimentadas pela primeira vez. O aconselhamento se sintetizava na proposta de prover uma preparação gradual, "passo a passo”, por um período longo de tempo, em lugar de uma atitude brusca que desse contornos de crise ao que era um processo "natural". Mostrar à filha o que acontecia com ela ou com outras mulheres da família e como elas cuidavam de seus corpos durante o período menstrual, era discutido como uma forma de demonstração de que nada de assustador iria acontecer.

A ausência da figura paterna nas consultas é uma constante. Foram raríssimas as vezes, em dois anos e meio de observação, que se presenciou a participação do pai. Quando ela se deu foi em consultas de primeira vez, nas quais se pauta a confirmação ou não do diagnóstico. Talvez isso explique, em certa medida, a baixa freqüência com que os problemas articulados à sexualidade dos meninos e adolescentes homens apareceram. As anotações do diário de campo só registram um caso em que a masturbação foi abordada espontaneamente por uma mãe, trazendo de forma explícita a conotação de conquista usualmente vinculada à noção de normalidade. Tratava-se de um caso já confirmado de mosaicismo em um menino de doze anos. A mãe fez questão de tocar no assunto, afirmando que a puberdade de seu filho ocorria dentro dos "padrões normais" e que ele "sa- bia se comportar", indo para seu quarto. Segundo ela, por isso: "Não brigo e também não dou muita atenção”.

O namoro também é encarado como indício da normalidade e é motivo de contentamento, com as mães estimulando as filhas a falarem sobre ele, uma vez que parte delas a informação. O médico, nesses casos, dirige-se à adolescente e pergunta como é o namorado. As respostas variam de artistas de televisão a pessoas comuns, porém é patente uma espécie de mimetismo, aliás componente da construção social da idéia de criança com síndrome de Down que encontra respaldo na literatura especializada, reproduzindo-se o olhar brincalhão da mãe ou gestos ordinariamente associados à concepção de namoro, tais como piscar os olhos, olhar de soslaio para os que estão em volta, entrelaçar as mãos e balançar-se, rodopiar, cobrir o rosto mas deixando os dedos entreabertos para mostrar o sorriso... Em nenhuma das vezes inquietações ou perguntas sobre o futuro foram exprimidas, ressaltando-se somente o presente, com o despertar e o exercício da sexualidade funcionando como metáfora de saúde e avanço em oposição à deficiência mental.

Focando-se apenas a condição síndrome de Down, a questão fundamental da historicidade trazida pelo pintor Paul Gauguin: "De onde viemos, quem somos e para onde vamos?", talvez para os pais das crianças com trissomia do cromossomo 21, seja respondida, em sua primeira parte, pelo acidente genético, na segunda pela metáfora da especialidade do anjo e na terceira pelo desafio de um futuro que se traz para o presente e que sempre será tingido pelos momentos passados, especialmente aquele em que se soube que o filho havia nascido com a marca da deficiência mental.

\section{Conclusão}

Em que pesem as transformações vertiginosas que a medicina vem sofrendo, ela permanece tendo como campo de aplicação o humano e dentro dele transita, tentando domá-lo, via o contorno definido dos elementos orgânicos que o compõe. Mas, esse trânsito é regulado por uma dinâmica na qual as clássicas divisões entre sujeito e objeto, mortos e vivos, natureza e cultura, máquinas e organismos, o "eu" e os outros, implodiram diante da realidade do avanço das tecnobiociências.

No caso de uma condição incurável, geneticamente determinada, como a que aqui se observou, aos recursos tecnológicos mais avan- 
çados juntou-se a perspicácia clínica, mas, de modo geral, não se evitou o processo de antropomorfização da enfermidade que contribui para a construção social de uma idéia homogênea acerca da criança com síndrome de Down.

A literalidade conferida à metonímia da substituição do paciente pela doença, diante da materialidade de um cromossomo a mais no par 21, influencia a maneira pela qual se organiza culturalmente a história de vida dos indivíduos com a síndrome, implicando o perigo de se estatuir para eles um futuro estanque e previsível, como também sua transformação num conjunto de genes que lhes ditaria a essência.

Para se dar conta da significação do conhecimento médico e de seu conteúdo semiótico, sem dúvida é imperioso entender que as práticas lingüísticas não são mediadas por sentidos convencionais, línguas, crenças, mas por situações parcialmente compartilhadas que possuem uma história, em que pese esta história estar permeada por tradições, hábitos e credos culturalmente enraizados, por mais que passíveis de serem modificados.

Nesse sentido, os registros sobre a síndrome de Down, elaborados nessa pesquisa etnográfica, refletem momentos históricos compartilhados, mutualmente construídos; todavia, produtos de conhecimentos diferenciados que falam com base em posições diferentemente estruturadas pelo gênero, raça, formação, nacionalidade e inserção social e cultural de classe. Formulados por médicos, pais/responsáveis, crianças com síndrome de Down e pela pesquisadora mostraram signos e sinais reveladores de produção de sentidos sobre o passado, o presente e o futuro. E se moveram dentro de uma "circularidade de idéias", tendo como finalidade comum um vir a ser qualitativamente melhor a ser compartilhado entre quem os produziu e aqueles que se importarem em lê-los.

\section{Referências}

ADLER, P. A. \& ADLER, P., 1998. Observacional techniques. In: Collecting and Interpreting Qualitative Materials (N. K. Denzin \& Y. S. Lincoln, ed.), pp. 79-109, London: Sage Publications.

GINZBURG, C., 1989. O Queijo e os Vermes. O Cotidiano e as Idéias de um Moleiro Perseguido pela Inquisição. São Paulo: Companhia das Letras.

GINZBURG, C., 1991. Chaves do mistério: Morelli, Freud e Sherlock Homes. In: O Signo dos Três (U. Eco \& T. Sebeok, org.), pp. 90-129, São Paulo: Editora Perspectiva.

HARAWAY, D., 1997.Modest_Witness@second_millenium.Female $\bigodot_{\text {_Mets_OncoMouse }} \mathrm{TM}^{\mathrm{TM}}$.Feminism and Technoscience. New York: Routledge.

SWEETMAN, D., 1998. Paul Gauguin. Uma Vida. Rio de Janeiro/São Paulo: Editora Record.

Recebido em 25 de fevereiro de 2002

Versão final reapresentada em 7 de junho de 2002

Aprovado em 5 de julho de 2002 